\title{
MOVIMENTOS SOCIAIS E AGROECOLOGIA NA AMAZÔNIA: UM ESTUDO DE CASO SOBRE O ASSENTAMENTO PAULO FONTELLES NA ILHA DO MOSQUEIRO EM BELÉM-PA
}

\author{
Devid Sivaldo da Silva Corrêa $^{(a)}$, Rosivaldo Galvão Ferreira ${ }^{(b)}$ \\ (a) Discente da Faculdade de Tecnologia em Geoprocessamento, UFPA, deividcorrea@gmail.com.br \\ (b) Discente da Faculdade de Tecnologia em Geoprocessamento, UFPA, rosivaldogalvao@bol.com.br.com.br
}

Eixo: Uso e ocupação das terras e legislação ambiental

\begin{abstract}
Resumo
O estudo de caso apresentado tem a finalidade de mostrar as formas de organização para a cooperação na criação e na gestão do Projeto de Assentamento Paulo Fontelles, em Mosqueiro, Belém - Pará. A problemática desse trabalho é fundamentada em compreender como os movimentos sociais influenciam nas formas de cooperação para a criação e gestão do Projeto do Assentamento e como a Agroecologia articula nas diferentes áreas do conhecimento desenvolvendo sistemas sustentáveis em todas as suas dimensões. O objetivo comum para a conquista da terra é o que garantiu o engajamento e a cooperação para a ocupação da área pelos movimentos sociais como MST que conseguiu junto aos órgãos competentes autorização para implantação do projeto que beneficia muitas famílias em situação de vulnerabilidade social.
\end{abstract}

Palavras chave: Assentamento. Movimentos Sociais. Agroecologia.

\section{Introdução}

O processo histórico dos assentamentos rurais na região metropolitana de Belém mostra as contradições existentes neste meio, como o aumento da concentração fundiária e as desigualdades nas relações de trabalho, trazendo mudanças no modo de vida de algumas comunidades, gerando um processo de lutas cada vez maior no cenário agrário local, que se combina com a política de criação de assentamentos rurais, apesar de estar implementada no I Plano Nacional de Reforma Agrária (PRNA), proposto, pelo governo, em 1985.

Segundo Scherer-Warren (1996) os movimentos sociais anteriores ao período da ditadura caracterizavamse por seu caráter paternalista e clientelista, ao mesmo tempo que o sindicalismo até então era atrelado ao Estado (autoritário) e de cunho assistencialista. A partir desta ideia, identifica-se que os processos de lutas consolidaram diversos movimentos sociais, pelo direito a terra e criar condições de subsistência das populações menos favorecidas pelas políticas públicas, dentre eles, o Movimento dos Trabalhadores Rurais Sem Terra (MST), surgido em 1979, garantiu o direito de legalização e desapropriação de terras antes improdutivas pelo estado. 


\section{OS DESAFIOS DA GEOGRAFIA FÍSICA NA FRONTEIRA DO CONHECIMENTO \\ Instituto de Geociências - Unicamp \\ Campinas - SP \\ 28 de Junho à 02 de Julho de 2017}

A Agroecologia integrada aos movimentos sociais agrários busca analisar processos ecológicos, econômicos, sociais e culturais sob uma perspectiva dos sistemas de produção existentes e vivenciar as realidades e experiências de produção e manejo sustentável no assentamento Paulo Fontelles no município de Belém, distrito de Mosqueiro, gerando um importante material de estudo e pesquisa que contribuirá para futuros projetos socioambientais em assentamentos e áreas com projetos de desenvolvimento sustentável.

Importante considerar, que as mudanças inspiradas pelos princípios da Agroecologia demandam a mobilização e o diálogo com um conjunto mais amplo de abordagens e campos do conhecimento. Diante deste enorme desafio nos remeteremos a compreender e contribuir com conhecimento científico de forma a minimizar a dependência de insumos externos, principalmente, de fontes não renováveis, de forma a garantir sua resiliência e autonomia, atributos importantes de sustentabilidade e dos movimentos sociais.

\section{Metodologia}

Neste estudo de campo, utilizou-se o método de observação direta através de entrevistas com questionários semiestruturados em visitas às famílias assentadas.

Para YIN (1989), a utilização do Estudo de Caso deve se dar quando os estudos de eventos contemporâneos, onde os comportamentos relevantes não podem ser manipulados, assim é possível se fazer observações diretas e entrevistas metódicas. Mesmo tendo pontos em comum com o método histórico, o Estudo de Caso caracteriza-se pela "[...] capacidade de lidar com uma completa variedade de evidências - documentos, artefatos, entrevistas e observações." (YIN, 1989, p. 19)

No Estudo de caso pode-se utilizar a observação direta, que consiste na visitação do local de estudo, onde um observador preparado pode fazer observações e coletar evidências sobre o caso que está sendo estudado. "Estas evidências geralmente são úteis para prover informações adicionais sobre o tópico em estudo." (YIN, 1989, p.91). Para acrescer a fidedignidade das observações, além de já ter roteiro definido, pode-se indicar mais de um observador e, em seguida as observações, catalogar os resultados obtidos das observações relatadas afim de eliminar erros.

A região Amazônica sempre foi caracterizada por sua complexa e extensa diversidade, onde desde sempre a agroecologia foi utilizada por seus povos e comunidades tradicionais como forma de subsistência na região. Assim, para Caporal, Costabeber e Paulus:

como ciência integradora a Agroecologia reconhece e se nutre dos saberes, conhecimentos e experiências dos agricultores(as), dos povos indígenas, dos povos da floresta, dos pescadores(as), das comunidades quilombolas, bem como dos demais atores 


\section{OS DESAFIOS DA GEOGRAFIA FÍSICA NA FRONTEIRA DO CONHECIMENTO \\ Instituto de Geociências - Unicamp \\ Campinas - SP \\ 28 de Junho à 02 de Julho de 2017}

sociais envolvidos em processos de desenvolvimento rural, incorporando o potencial endógeno, isto é, presente no "local". No enfoque agroecológico o potencial endógeno constitui um elemento fundamental e ponto de partida de qualquer projeto de transição agroecológica, na medida em que auxilia na aprendizagem sobre os fatores socioculturais e agroecossistêmicos que constituem as bases estratégicas de qualquer iniciativa de desenvolvimento rural ou de desenho de agroecossistemas que visem alcançar patamares crescentes de sustentabilidade. (2006, p. 46)

A metodologia obedeceu ao princípio analítico-descritivo com base na observação das estruturas organizacionais do assentamento, fazendo uso da correlação entre a teoria disponibilizada e as práticas sociais observadas através da visita de campo referente a disciplina Sociedade e Território na Amazônia.

O relato de algumas famílias nos fez compreender em como o contexto histórico de uma comunidade e o seu esforço em garantir um futuro para a suas famílias se aliam ao poder político, social e econômico fortalecendo assim seus laços com a terra e permitindo as futuras gerações uma consolidação dos seus direitos e deveres em relação ao espaço em que vivem.

\section{Resultados Obtidos}

O assentamento surgiu a partir do aval do filho do deputado Paulo Fontelles, que foi assassinado por questões fundiárias da região, e permitiu que o MST ocupasse a área dando continuidade a outro assentamento na estrada do Maraú chamado Elisabeth Teixeira, na época o grande número de famílias que ocuparam a área necessitava de um espaço maior para se estabelecer, nesse sentido a área que hoje é ocupada por 28 famílias advindas do assentamento anterior, não realizou um trabalho de base para mobilização e organização dessas famílias.

Com o resultado desse estudo pretendemos desvendar as interfaces dos projetos nesse e em outras comunidades que se organizam por meio dos movimentos sociais e articulam para a melhoria das atividades socioeconômicas.

O monitoramento e a verificação das áreas do assentamento são realizados pelas técnicas de Georreferenciamento e pelas informações estabelecidas no CAR, como limites das áreas para produção, construção e reservas legais.

A questão de acesso à educação nessas áreas já está atingindo índices satisfatórios para filhos de alguns analfabetos e semianalfabetos que têm seus filhos estudando em universidades públicas e particulares através do sistema de cotas. Segundo o Professor Marcelo, está sendo realizado um esforço dentro do Campus de Ananindeua para o estabelecimento de dois cursos, um de Educação do Campo e outro de Tecnólogo em Agroecologia com prioridade para estudantes assentados, quilombolas, e moradores da zona rural, com oferta para Ananindeua e Abaetetuba em regime de intercâmbio, com intuito de dar 
visibilidade para as comunidades rurais existentes na nossa região, onde somente na área metropolitana de Belém encontramos 39 ilhas com inúmeros extrativistas, assentados, quilombolas, pescadores, etc.

Incentivar a pesquisa e os resultados, fundamentar-se em instrumentos para a construção de um pensamento pratico-teórico das disciplinas aplicadas no curso, trarão benefícios a médio e longo prazo para comunidades e famílias que antes estavam longe de concretizar projetos e planejar as futuras ações em conformidade com as leis e o meio ambiente.

\section{Conclusões}

Este trabalho nos possibilitou ter uma visão ampliada sobre a complexidade de se construir e manter um assentamento em conformidade com as exigências georreferenciais, sociais e econômicas da lei que ampara tais projetos.

Estudar suas particularidades e abrir novos nichos de pesquisas nos leva a busca de novas soluções para os problemas enfrentados nessas comunidades e pelas famílias que veem no Movimento Sem Terra um referencial de manifestação e luta pela terra. O MST ressalta que para se buscar um desenvolvimento rural, é importante mudar o modelo agrário do nosso país, tão quanto a relação entre os homens, como o modo de enxergar a natureza. Dessa forma o Movimento Sem Terra vem estudando e buscando construir em conjunto com analistas e trabalhadores do meio rural uma proposta alternativa para o atual modelo.

Assim, a agroecologia e vista como uma nova saída do MST para a agricultura nos assentamentos, onde há de se ressaltar que não se trata apenas de uma pratica muito menos uma técnica, e sim uma forma de se observa o funcionamento dos sistemas. Sendo assim, a agroecologia busca agregar cultivos com associações, rotações, permitindo assim uma maior produtividade por área.

\section{Bibliografia}

CAPORAL, Francisco Roberto; COSTABEBER, José Antônio; PAULUS, Gervásio. Agroecologia: matriz disciplinar ou novo paradigma para o desenvolvimento rural sustentável. Princípios e Perspectivas da Agroecologia, Curitiba, v. 1, p. 45-80, 2006. Disponível em: <www.agroeco.org/socla/ archivospdf/AgroecologiaNovoParadigma02052006-ltima Verso1.pdf>. Acesso em: 11 abr. 2017.

GOHN, M. G. Teorias dos movimentos sociais: paradigmas clássicos e contemporâneos. Edições Loyola, $3^{\mathrm{a}}$ ed, São Paulo, 2002. 
GLIESSMAN, Stephen. R. Agroecologia: processos ecológicos em agricultura sustentável. Porto Alegre: UFRGS, 2000.

SCHERER-WARREN, Ilse. Redes de movimentos sociais. Edições Loyola, 2a ed, São Paulo, 1996.

YIN, Robert K. - Case Study Research - Design and Methods. Sage Publications Inc., USA, 1989. 